\title{
Establishment of the vertebrate kinetochores
}

\author{
Tetsuya Hori • Tatsuo Fukagawa
}

Published online: 26 June 2012

(C) Springer Science+Business Media B.V. 2012

\begin{abstract}
The centromere is essential for accurate chromosome segregation during mitosis and meiosis to achieve transmission of genetic information to daughter cells. To facilitate accurate chromosome segregation, the centromere serves several specific functions, including microtubule binding, spindle-checkpoint control, and sister chromatid cohesion. The kinetochore is formed on the centromere to achieve these functions. To understand kinetochore structure and function, it is critical to identify the protein components of the kinetochore and characterize the functional properties of each component. Here, we review recent progress with regard to the molecular architecture of the kinetochore and discuss the future directions for centromere biology.
\end{abstract}

Keywords Centromere $\cdot$ Kinetochore $\cdot \mathrm{CCAN} \cdot \mathrm{KMN}$
Abbreviations
AFM Atomic-force microscopy
CCAN Constitutive centromere-associated network
CENP Centromere protein
ChIP Chromatin immunoprecipitation

Responsible Editor: Rachel O'Neill and Beth Sullivan.

T. Hori $(\bowtie) \cdot$ T. Fukagawa $(\bowtie)$

Department of Molecular Genetics,

National Institute of Genetics and the Graduate

University for Advanced Studies,

Mishima, Shizuoka 411-8540, Japan

e-mail: thori@lab.nig.ac.jp

e-mail: tfukagaw@lab.nig.ac.jp
CPC Chromosome passenger complex

FACT Facilitates chromatin transcription

FRAP Fluorescence recovery after photobleaching

EM Electron microscope

GFP Green fluorescent protein

GST Glutathione S-transferase

HP1 Heterochromatin protein 1

KMN KNL1 and the Mis12 and Ndc80 complexes

$\mathrm{LacO}$ Lac (lactose operon) operator

LacI Lac repressor

PP1 $\gamma \quad$ Protein phosphatase 1 gamma

RFP Red fluorescent protein

\section{Introduction}

Cell division is a critical biological process for transmitting genetic information to daughter cells in all organisms. As we can observe chromosome behavior during cell division under a classic microscope, studies on chromosome segregation are one of the traditional research areas in biology. For faithful chromosome segregation, each sister chromatid must attach to spindle microtubules. This attachment is mediated by a large proteinaceous structure called the kinetochore that forms on centromeric DNA. Direct observation using an electron microscope (EM) reveals that the kinetochore has a trilaminar structure composed of electron-dense inner and outer layers (Brinkley and Stubblefield 1966; Jokelainen 1967). It is unclear which molecules are involved in the 
formation of this tri-layered structure. Genetic screens and recent biochemical and proteomic analyses have identified more than 100 proteins that localize to the kinetochore, but we are still far from completely understanding how those proteins work coordinately to form a functional kinetochore (Cheeseman and Desai 2008; Perpelescu and Fukagawa 2011; Takeuchi and Fukagawa 2012). To ensure accurate chromosome segregation, the kinetochore has three key activities (Fig. 1): First, the kinetochore must be specified at a single locus on each chromosome in most eukaryotes; if the kinetochore is formed at multiple loci on a chromosome, it is possible for the same chromatid to become simultaneously attached to opposite spindle poles, and this results in chromosome instabilities, which lead to cell death or carcinogenesis. Second, the kinetochore must form an interface to attach to the spindle microtubules; to form a functional kinetochore, various proteins must be assembled and be modified before mitosis. Third, sister kinetochores must be held together by sister-chromatid cohesion. This contributes to proper bipolar attachment of kinetochores to the spindle and silences/satisfies the spindle-checkpoint pathway.

Recent progress has revealed that a group of 16 chromatin-proximal proteins, referred to as the constitutive centromere-associated network (CCAN) (Fig. 1), is largely involved in establishing a foundation for the kinetochore structure (Perpelescu and Fukagawa 2011; Takeuchi and Fukagawa 2012). External to this, the KMN (KNL1 and the Mis12 and Ndc80 complexes) network recognizes the CCAN to form a functional kinetochore (Fig. 1). In this review, we introduce and discuss the latest insights in kinetochore research, including the CCAN and KMN network and their functional roles in kinetochore formation.

\section{Centromeres are specified by sequence-independent epigenetic mechanisms in vertebrates}

For centromere specification, it is easy to imagine that the underlying primary DNA sequence may provide important information. Indeed, the budding yeast Saccharomyces cerevisiae has a short, unique 125-bp sequence for specifying the centromere (Clarke and Carbon 1980; Wiens and Sorger 1998). In vertebrates, large arrays of tandem-repeated DNA have been found at specific chromosomal domains, including constitutive heterochromatin and centromeres using classical molecular biological approaches. Although centromeric-satellite DNA is highly divergent in various organisms, unit sequences of repeats are usually similar among the chromosomes of each organism. Human centromeres typically contain mega-base arrays of tandem-repeated 171-bp alpha-

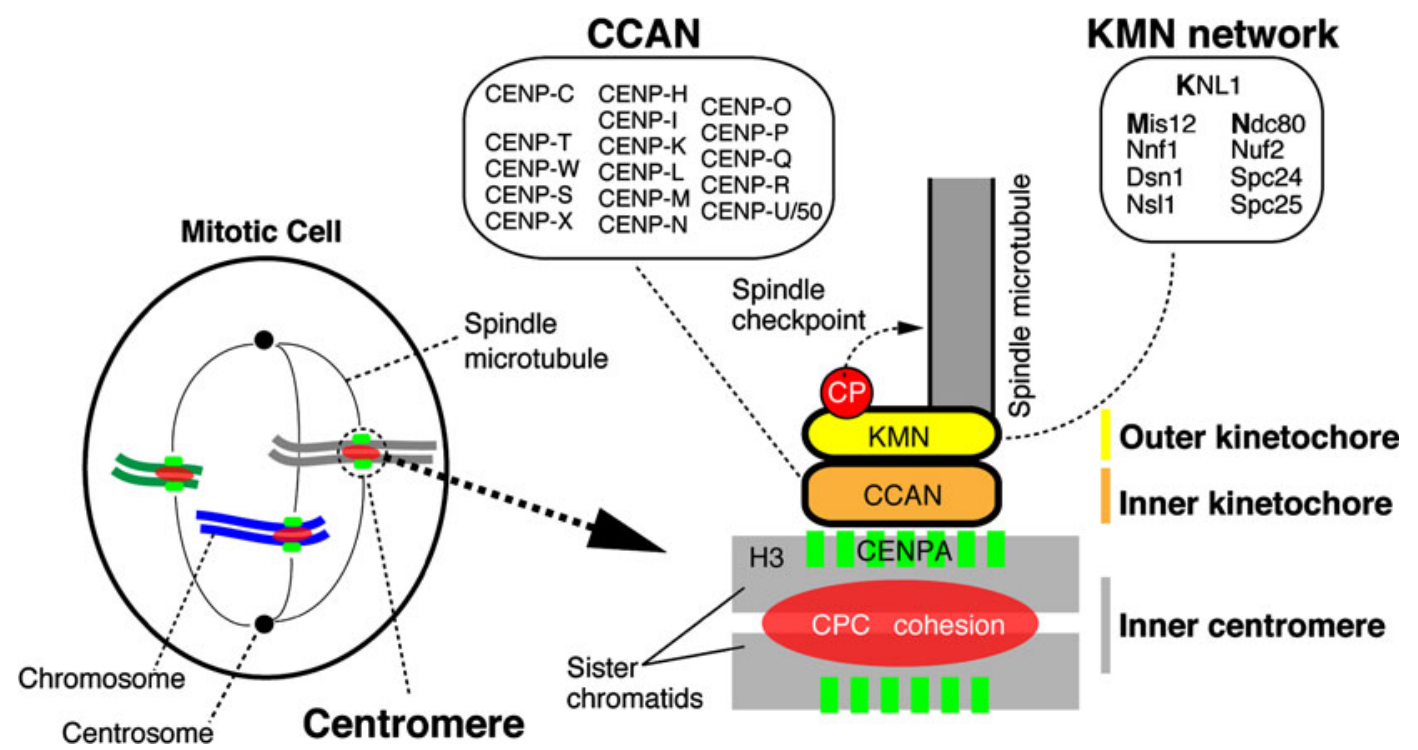

Fig. 1 Architecture of the vertebrate kinetochore in mitotic cells. The kinetochore is assembled on a single locus on each chromosome specified by sequence-independent epigenetic mechanisms. The kinetochore is divided into two major protein networks: the CCAN and the KMN network. The CCAN localizes to centromeres throughout the cell cycle and provides a structural platform for targeting of the KMN network during mitosis 
satellite DNA (Fig. 2) (Willard 1990). Alpha-satellite DNA is recognized by centromere protein B (CENP-B) and contributes to efficient de novo centromere formation in human artificial chromosomes (Harrington et al. 1997; Ikeno et al. 1998; Ohzeki et al. 2002). However, CENP$\mathrm{B}$ is not essential for the maintenance of native centromeres, because CENP-B knockout mice are viable (Hudson et al. 1998; Kapoor et al. 1998; Perez-Castro et al. 1998). Furthermore, discovery of neocentromeres where a functional kinetochore is established in the absence of alpha-satellite DNA demonstrates that alphasatellite DNA sequences are not absolutely essential for kinetochore formation (du Sart et al. 1997; Marshall et al. 2008). Analysis of histone modifications at some human neocentromeres by chromatin immunoprecipitation (ChIP) using antibodies against tri-methylated K9 of histone $\mathrm{H} 3$ have revealed a lack of heterochromatin enrichment around each neocentromere, suggesting that large domains of heterochromatin are not required for centromere formation (Alonso et al. 2010). This is in contrast to the case of fission yeast or Drosophila, in which heterochromatin facilitates kinetochore formation (Folco et al. 2008; Ishii et al. 2008; Olszak et al. 2011). However, sister chromatid cohesion is weaker than normal at human neocentromeres (Alonso et al. 2010). In addition, Aurora B does not localize at the proper position in human neocentromeres, potentially causing defects in error correction of kinetochore-microtubule attachments (Bassett et al. 2010). These reports suggest that heterochromatin formed on a highly repetitive array is dispensable for kinetochore formation but provides additional activities for a fully functional kinetochore to mediate faithful chromosome segregation in human cells.

Recent deep-sequencing or ChIP-chip analyses for centromere-associated DNA in various organisms revealed that some chromosomes do not contain tandem repetitive sequences. These include chicken chromosomes 5, 27, and Z or horse chromosome 11 (Fig. 2) (Shang et al. 2010; Wade et al. 2009). These findings, together with the discovery of human neocentromeres, indicate that tandem-repetitive DNA is not essential for kinetochore formation. The position of neocentromeres

\section{Human}

Long repetetive $\alpha$-satellite array in all centromeres

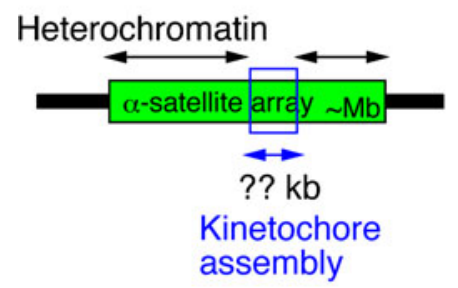

\section{Chicken}

Long repetitive array in most centromeres
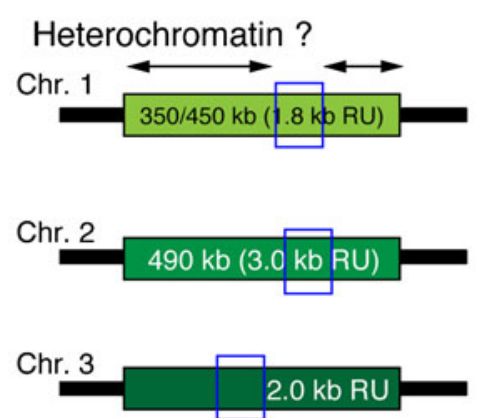

Kinetochore assembly
Non-repetitive sequence at Chr. 5, 27, and Z Cen.

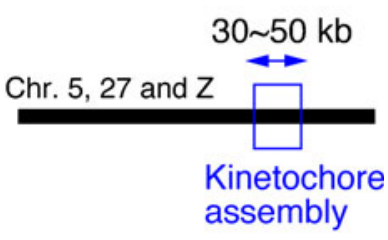

Fig. 2 Organization of centromeric DNA in human and chicken cells. Human centromeres typically contain large tandem-repeated alpha-satellite sequences. Such large repeated sequences may not be essential for centromere formation but may be responsible for the generation of a robust centromere, which contains heterochromatin near the core centromere region. It is hard to determine the exact size of the core region of centromeres on which kinetochores are formed. Whereas most chicken centromeres possess large tandem-repeated sequences analogous to those in humans, three chromosomes $(5,27$, and $Z)$ possess non-tandem-repeated sequences as centromeric DNA. The sizes of non-repetitive centromeres of chickens occupied by CENP-A are $30-50 \mathrm{~kb}$ long. As the amount of CCAN proteins on non-repetitive centromeres is similar to that on centromeres with repetitive arrays (Johnston et al. 2010), the core region for centromeres may also be as little as $30-50 \mathrm{~kb}$ in centromeres with long repetitive arrays 
and native centromeres without repetitive sequences is inherited by the next generation, suggesting that the kinetochore is specified by sequence-independent epigenetic mechanisms. Many previous studies have supported this idea and centromere-specific hisotone $\mathrm{H} 3$ variant CENP-A serves as an epigenetic mark for kinetochore specification (Black and Cleveland 2011; Vafa and Sullivan 1997; Warburton et al. 1997). However, considering the fact that most chromosomes usually have a centromere with a repetitive DNA sequence in vertebrate cells, we would like to propose that centromeres with non-repetitive sequences may be immature centromeres that are created by centromere repositioning, and that tandem-repetitive sequences were subsequently added during the process of evolution to form stable centromeres (Shang et al. 2010).

\section{CCAN serves as a core structure on centromeric chromatin}

As centromeres are specified by sequence-independent epigenetic mechanisms, it is essential to understand how centromeric chromatin is established and how centromeric chromatin is linked to spindle microtubules. To address these questions, it is critical to identify a complete list of kinetochore components and characterize them. Initially, three kinetochore components were identified from sera of patients with autoimmune diseases and referred to as CENP-A, -B, and -C (Earnshaw and Rothfield 1985; Moroi et al. 1980). CENP-A is a centromere-specific histone $\mathrm{H} 3$ variant (Palmer et al. 1987) and is incorporated into centromeric DNA as a nucleosome (Tachiwana et al. 2011), which is an important epigenetic mark for kinetochore specification (Black and Cleveland 2011). Analyses of dicentric chromosomes have revealed that CENP-A is incorporated only at active centromeres, but not at inactive ones, which supports the idea that CENP-A provides an epigenetic marker for kinetochore specification. CENP-B is a DNA-binding protein that specifically recognizes the 17-bp sequence called a CENP-B box in alphasatellite DNA (Masumoto et al. 1989). CENP-B is not essential for kinetochore formation. However, CENP-B enhances the efficient de novo formation of human artificial chromosomes through binding to the CENP$\mathrm{B}$ box, suggesting that CENP-B binding to DNA may play some role in establishing the kinetochore (Okada et al. 2007). In addition to CENP-A and CENP-B, CENP-
C is also a DNA-binding protein (Saitoh et al. 1992; Yang et al. 1996) and, therefore, these three proteins should contribute to the establishment of centromeric chromatin. Importantly, CENP-A and CENP-C are found only at active centromeres, whereas CENP-B is also found at inactive centromeres on stable dicentric chromosomes (Earnshaw et al. 1989; Sullivan and Schwartz 1995). Following the identification of CENP-A, -B, and -C, CENP-H and -I were then identified as proteins that localize to kinetochores throughout the cell cycle (Fukagawa et al. 2001; Nishihashi et al. 2002; Sugata et al. 1999).

Since the identification of CENP-A, -B, -C, -H, and -I, three laboratories have independently performed a proteomic approach and identified an additional 13 proteins that are associated with centromeric chromatin in both chicken and human cells (Perpelescu and Fukagawa 2011; Takeuchi and Fukagawa 2012). These proteins are referred to as CCAN (Fig. 1). Based on gene knockouts in chicken DT40 cells and knockdown experiments with RNAi in human cells, the CENP-A-containing nucleosome stands the furthest upstream in the localization hierarchy, because CENP-A disruption causes mislocalization of all CCAN proteins (Liu et al. 2006; Regnier et al. 2005). Based on biochemical, functional, and structural analyses, CCAN proteins are divided into at least four sub-complexes: CENP-C, CENP-T-W-S-X, CENP-H-I-K-L-M-N, and CENP-O-P-Q-R-U (Fig. 3) (Cheeseman and Desai 2008; Hori et al. 2008a; 2008b; Nishino et al. 2012; Okada et al. 2006).

CENP-C is a kinetochore-specific protein with DNA binding activity (Saitoh et al. 1992; Yang et al. 1996). As CENP-C binds to DNA, it is possible that CENP-C associates with CENP-A-containing nucleosomes. However, ChIP experiments revealed that CENP-C strongly associates with canonical histone H3-containing nucleosomes when chromatin is completely digested with micrococcal nuclease (MNase) into mono-nucleosomes (Ando et al. 2002; Hori et al. 2008a; Obuse et al. 2004b). When polynucleosomes with partial MNase digestion were used, CENP-A was co-precipitated with CENP-C, suggesting that CENP-C binds to H3containing nucleosome adjacent to CENP-A-containing nucleosomes. On the other hand, in vitro biochemical experiments demonstrated that the six amino acids on the $\mathrm{C}$ terminus of CENP-A interact with the middle region of CENP-C, and these residues are essential for kinetochore assembly in Xenopus egg extracts (Carroll et al. 2010; Guse et al. 2011). Considering these results, we 
Kinetochore

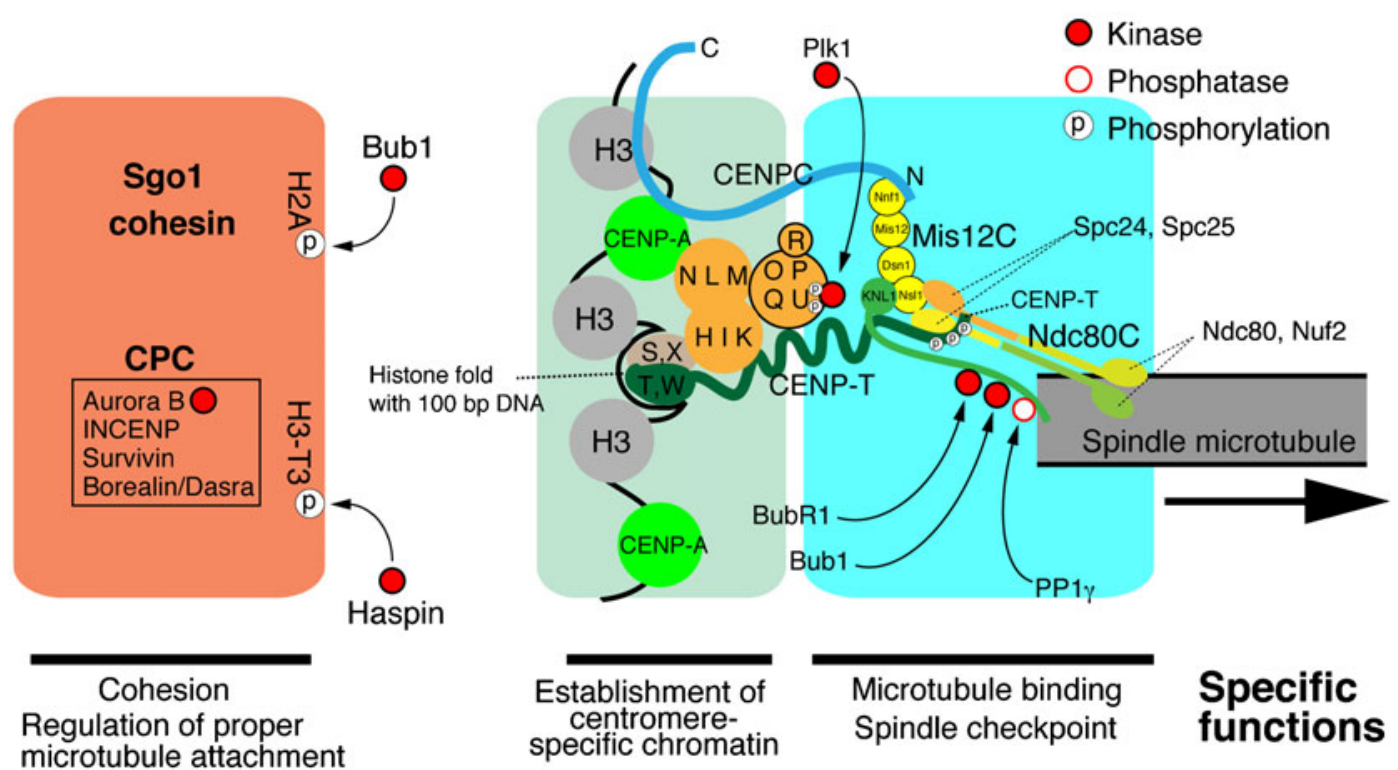

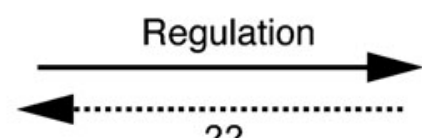

??

Fig. 3 Molecular organization of centromere and kinetochore in vertebrate cells. The inner centromere structure underlies the kinetochore. The inner centromere is responsible for the centromeric cohesion between sister chromatids established by cohesion complex, Shugoshin (Sgo1) and the chromosome passenger complex (CPC). Localization of both Sgol and CPC is related with phosphorylation of $\mathrm{H} 2 \mathrm{~A}$ by Bub1 kinase and histone $\mathrm{H} 3 \mathrm{~T} 3$ by haspin kinase, respectively (Kelly et al. 2010; Wang et al. 2010; 2011; Yamagishi et al. 2010). CENP-A-containing nucleosomes function as epigenetic marks for kinetochore specification. In addition to CENP-A, CENP-C, and the CENP-T-W-S-X complex, other

suggest that CENP-C interacts with CENP-A, leading to kinetochore assembly, but also binds adjacent the H3containing nucleosomes to establish strong contacts with centromeric chromatin. Ribeiro et al. (2010) performed a kinetochore unfolding assay and demonstrated that CENP-C is required for the structural integrity of mitotic kinetochore chromatin. Disruption of CENP-C causes a strong reduction in kinetochore localization of the Mis 12 complex, which associates with the microtubule-binding Ndc80 complex (Kwon et al. 2007; Liu et al. 2006; Milks et al. 2009). Biochemical experiments demonstrated that a conserved N-terminal region of CENP-C binds directly to the Mis12 complex and this interaction appears to be stoichiometric (Screpanti et al. 2011). In addition, a GST pull-down experiment revealed that the
CCAN components are involved in the establishment of centromeric chromatin. Both CENP-C and CENP-T connect the chromatin to the KMN components. Phosphorylation of the CENP-TN terminus is essential for its stable interaction with the Ndc80 complex that directly binds spindle microtubules. Nsll of the Mis12 complex and KNL1 also contribute to stabilizing the interaction of the Ndc80 complex with the inner kinetochore. Several kinases and phosphatases, including BubR1, Bub1, Plk1, and $\mathrm{PP} 1 \gamma$, are recruited to kinetochores. Phosphorylation of kinetochore proteins is involved in the spindle-checkpoint pathway or the establishment of proper kinetochore microtubule attachments

CENP-C N terminus binds Nnf1, a subunit of the Mis12 complex (Przewloka et al. 2011). Furthermore, ectopic localization of the CENP-C N terminus into the centrosomes induced an accumulation of KMN on centrosomes in Drosophila cells (Przewloka et al. 2011). Based on this evidence, we propose that CENP-C is a strong candidate for a linker molecule between centromeric chromatin and the microtubule binding components of the outer kinetochore.

The CENP-T-W-S-X complex is also a DNAbinding complex at kinetochores. CENP-T and CENP$\mathrm{S}$ were originally identified by mass spectrometry analysis in CENP-A-containing polynucleosomes (Foltz et al. 2006). Following identification of these proteins, we identified CENP-W as a CENP-T-associated protein 
(Hori et al. 2008a) and CENP-X as a CENP-S-associated protein in both human and chicken cells (Amano et al. 2009). Both CENP-T and CENP-W possess histone-fold domains, and these two proteins form a tight complex that shows DNA binding activity. To test whether the CENP-T-W complex directly binds to the CENPA-containing nucleosome, we performed ChIP experiments and detected only histone $\mathrm{H} 3$ with the mononucleosomal chromatin fraction associated with CENPT-W but detected both H3 and CENP-A with the polynucleosomal chromatin fraction. This result suggests that the CENP-T-W complex associates with canonical H3-containing nucleosomes, but not with CENP-Acontaining nucleosomes (Hori et al. 2008a). Observation of centromeric chromatin by a super-resolution microscope supports this conclusion (Ribeiro et al. 2010).

Both CENP-S and CENP-X also have histone-fold domains and form a tight complex similar to the CENPT-W complex (Nishino et al. 2012). These two complexes possess similar structural features and CENP-T or -W was detected as a CENP-S-interacting protein based on high-sensitivity mass spectrometry analysis (Amano et al. 2009). Nevertheless, the phenotype of CENP-T-W depletion is different from that of the CENP-S-X depletion. Whereas CENP-T-W depletion results in severe mitotic defects, the phenotype of CENP-S-X depletion is relatively mild (Amano et al. 2009). Thus, the relationship between these two complexes was unclear. However, our structural analysis on these two complexes has clearly shown that CENP-T, -W, -S, and -X form a heterotetramer that exhibits DNA supercoiling activity. We proposed that this complex forms a nucleosome-like structure (Nishino et al. 2012). Based on the structural analysis of the CENP-T-W-S-X complex, we identified amino acid residues responsible for the tetramer formation of CENP-T-W-S-X and examined the significance of this tetramer formation in vitro and in vivo. We created mutant CENP-T and CENP-S proteins that do not form a heterotetramer in vitro and used them to replace wild-type CENP-T or CENP-S with mutant CENP-T or CENP-S, respectively, in DT40 cells. We found that kinetochore localization of CENP-T or CENP-S was reduced and a functional kinetochore was not formed in these cells (Nishino et al. 2012). These data suggest that tetramer formation of the complex is essential for the establishment of centromeric chromatin to form a functional kinetochore.

CENP-T is a $\sim 600$-amino-acid protein whose Cterminal 100 -amino-acid region contains a histone- fold domain. The 500-amino-acid N-terminal region is predicted to be an unstructured domain whose exact function is unclear. We demonstrated that the extreme $\mathrm{N}$-terminal 100-amino-acid region of CENP-T is essential for the localization of outer kinetochore proteins including the Ndc80 complex (Gascoigne et al. 2011). In addition, biochemical experiments demonstrated that the recombinant human CENP-T-W complex associated with an engineered $\mathrm{Ndc} 80^{\mathrm{Bonsai}}$ complex (Gascoigne et al. 2011). These data suggest that CENP-T connects centromeric chromatin with outer kinetochores, as CENP-C does. As CENP-T localization is distinct from CENP-C, we proposed that there are two parallel pathways to connect centromeric chromatin with outer kinetochores (Hori et al. 2008a). Based on EM observations, we found that the distribution of centromeric chromatin is deformed by the tension from spindle microtubules during mitosis (Suzuki et al. 2011). Our idea is that the unstructured N-terminal 500-amino-acid region of CENP-T is responsible for this structural deformation of centromeric chromatin. We demonstrated that the Nterminal CENP-T region is flexible, based on highspeed atomic-force microscopy (AFM) analysis, and that CENP-T was stretched under tension in cells expressing GFP (N-terminus) and RFP (C-terminus) double-fused CENP-T. These results support our idea that a flexible CENP-T region is responsible for kinetochore stretching caused by tension from spindle microtubules (Suzuki et al. 2011).

CENP-H, -I, -K, -L, -M, and -N proteins were purified from CENP-A-containing polynucleosomes in human HeLa cells (Foltz et al. 2006; Izuta et al. 2006; Obuse et al. 2004b) or identified as CENP-H- and CENP-I-associated proteins in chicken DT40 cells (Okada et al. 2006). DT40 knockout cells for these proteins showed strong mitotic defects. As we observed that kinetochore localization of these six proteins is interdependent, we classified these proteins as a functional group. However, it is possible that this group can be divided into subgroups. CENP-H was originally identified as a constitutive centromeric coiled-coil protein from mouse and human cells (Sugata et al. 1999). CENP-I was identified as a vertebrate homologue of fission yeast Mis6 protein (Nishihashi et al. 2002; Saitoh et al. 1997). CENP-K was reported as Solt, which is a binding partner of transcriptional regulator SoxLZ/Sox6 (Yamashita et al. 2000). CENP-M was also reported as proliferation-associated nuclear element 1 (PANE1), which is highly expressed in proliferating cells such as 
activated lymphoid cells and tumors (Bierie et al. 2004; Renou et al. 2003). Although CENP-K or -M was originally identified in the context of transcription or cell proliferation, the relationship between kinetochore function and these biological events remains unclear.

Kinetochore localization of CENP-H group proteins is dependent on CENP-A, indicating that localization of these proteins into kinetochores occurs downstream of CENP-A (Okada et al. 2006; Regnier et al. 2005). Whereas CENP-A localization at the kinetochore is not altered in CENP-H-deficient cells, incorporation of newly synthesized GFP-CENP-A into kinetochores is impaired in CENP-H-, -I-, -K- and CENP-M-deficient cells (Okada et al. 2006). This suggests that the CENP-H group proteins are required for optimal deposition of newly synthesized CENP-A into centromeres. We proposed that the chromatinremodeling factor FACT (facilitates chromatin transcription) might facilitate CENP-A deposition coordinately with CENP-H group proteins (Okada et al. 2009). We demonstrated that kinetochore localization of FACT was dependent on CENP-H group proteins and CENP-A incorporation was abolished in FACTdeficient cells.

Carroll et al. (2009) demonstrated that CENP-N could directly bind CENP-A-containing nucleosomes in vitro. They also showed that the C-terminal region of CENP-N interacts with CENP-L. This interaction may facilitate kinetochore assembly. In addition, the CENP-H group proteins may be required for spindle-checkpoint function, as Mad1 or Mad2 kinetochore localization is reduced in cells depleted for CENP-I (Liu et al. 2003; Matson et al. 2012). Furthermore, Amaro et al. (2010) demonstrated that the CENP$\mathrm{H}$ group proteins were involved in molecular control of kinetochore-microtubule dynamics and chromosome oscillations. Although there have been some studies on the functional roles of the CENP-H group in kinetochores, the precise function of these proteins is still unclear. Whereas kinetochore localization of the CENP-H group occurs downstream of CENP-T, CENP-T signals are also reduced in CENP-H-deficient cells, suggesting that the CENP-H group is also involved in the formation of centromeric chromatin.

CENP-O, -P, -Q, -R, and -U are not essential for the growth of DT40 cells because DT40 knockout cells for these proteins are viable (Hori et al. 2008b). CENP$\mathrm{U}$ (50) was originally reported as MLF1IP or KLIP because this was isolated in the context of the development of erythroleukemias or transcriptional regulation (Hanissian et al. 2004; Pan et al. 2003). We identified this protein as an MgcRac-GAP-interacting protein and referred to it as CENP-50, as this $50-\mathrm{kDa}$ protein localizes to kinetochores throughout the cell cycle in chicken DT40 cells (Minoshima et al. 2005). After that, this was also referred as CENP-U (Foltz et al. 2006; Okada et al. 2006). DT40 cells with a depletion of CENP- U (50) are viable but show a slight mitotic delay. Whereas kinetochore localization of CENP-U (50) depends on CENP$\mathrm{H}$ or CENP-I, these proteins clearly localize to kinetochores in cells with CENP-U (50) depletion, suggesting that localization of CENP-U (50) occurs downstream of CENP-H group proteins. Based on iFRAP (inverse fluorescence recovery after photobleaching) experiments, CENP-U (50) stably associates with centromeres, like CENP-C and CENP-H (Minoshima et al. 2005). A proteomic approach identified CENP-O, -P, $\mathrm{Q}$, -R, and -U (50) in CENP-A-associated polynucleosomes from human cells (Foltz et al. 2006; Izuta et al. 2006) or CENP-H-I-associated proteins from chicken DT40 cells (Okada et al. 2006). As the phenotype of DT40 cells with depletion of each knockout cell line (CENP-O-, -P, -Q, -R, and -U-knockout) is similar, we classified these proteins as a functional subgroup (Hori et al. 2008b). We also performed co-expression of these five proteins simultaneously in Escherichia coli and demonstrated that these proteins form a stable complex (Hori et al. 2008b). Localization of CENP-O, -P, -Q, and -U is interdependent and CENP-R localization occurs downstream of these four proteins, suggesting that CENP-O, $\mathrm{P},-\mathrm{Q}$, and $-\mathrm{U}$ form a tight complex and that CENP-R associates with this complex (Hori et al. 2008b).

To uncover the roles of CENP-O complex proteins in mitosis, we examined mitotic progression following release from nocodazole block of cells depleted for CENP-O complex proteins. Interestingly, when CENP-U (50)-deficient cells are treated with nocodazole and the drug is subsequently washed out, these cells are arrested at prometaphase by activation of the spindle-assembly checkpoint, suggesting that CENP-O complex proteins are essential for recovery from spindle damage (Hori et al. 2008b; Minoshima et al. 2005). Kang et al. (2006) showed that human CENP-U (50) (they referred this protein as PBIP1) is phosphorylated at S77 and S78, and phosphorylation at these sites is 
essential for localization of polo-like kinase 1 (Plk1) in kinetochores. We confirmed that mutation of the corresponding residues in chicken CENP-U (50) (S62 and T63) caused a reduction of centromere localization of Plk1, particularly in the G2 phase (Hori et al. 2008b). In addition, cells in which expression of CENP-U (50) is replaced with that of the CENP-U (50) mutant show defects in recovering from spindle damage similar to the CENP-U (50) knockout cells, suggesting that phosphorylation of CENP- U (50) and Plk1 are involved in CENP-U (50) function during the recovery from spindle damage. Although the recruitment of Plk1 to kinetochores requires the CENP-O complex in the G2 phase, there are several pathways localizing Plk1 to kinetochores during prometaphase thorough BubR1 and INCENP (Elowe et al. 2007; Goto et al. 2006). We propose that one pathway may be dependent on phosphorylation of S62 and T63 of chicken CENP-U (50) in $\mathrm{G} 2$ or prometaphase. In this process, other CCAN proteins and/or CCAN-associated proteins might be phosphorylated particularly by Plk1 to establish proper kinetochores after spindle damage (Fig. 3) (Santamaria et al. 2011). Consistent with this hypothesis, Lenart et al. (2007) demonstrated that the number of microtubules attached to kinetochores is reduced in human cells treated with the Plk1 inhibitor BI2536, based on EM observation. In addition, phosphorylation of BubR1 by Plk1 contributes to stable kinetochore-microtubule interactions in human cells (Elowe et al. 2007).

\section{The KMN functions as an interface with spindle microtubules}

Once a centromere is specified by CENP-A and centromeric chromatin is established by the CCAN, the kinetochore must make robust interactions with spindle microtubules during mitosis to achieve accurate chromosome segregation. A key interface with spindle microtubules is the KMN network. KMN network components start to localize to kinetochores around the G2 phase and dissociate at the end of mitosis in vertebrate cells. The KMN network can be reconstituted using recombinant proteins and binds to tubulin in vitro (Cheeseman et al. 2006). Functional kinetochores during mitosis must possess multiple activities to undergo accurate chromosome segregation, including microtubule binding, spindle-assembly-checkpoint and sister chromatid cohesion in the inner centromere. As the
KMN network is essential for establishment of a functional kinetochore, components of the KMN network must possess critical functional properties (Fig. 3).

KNL1 was originally identified by an RNAi-based functional genomic screen in Caenorhabditis elegans (Desai et al. 2003) and later homologues were identified in other organisms (Cheeseman et al. 2004; Kerres et al. 2004; Nekrasov et al. 2003; Obuse et al. 2004a; Przewloka et al. 2007). KNL1 is a large protein ( $\sim 300 \mathrm{KDa}$ in human cells) and binds to other proteins at multiple KNL1-binding sites. KNL1 possesses microtubule-binding activity on its $\mathrm{N}$-terminal basic residues (Cheeseman et al. 2006; Pagliuca et al. 2009). Analysis of $C$. elegans KNL1 suggests that microtubule binding by KNL1 is involved in spindlecheckpoint silencing (Espeut et al. 2012). However, microtubule binding by KNL1 may not contribute to a major pulling force for chromosome segregation.

The N-terminal region of KNL1 binds to protein phosphatase 1 gamma (PP1 $\gamma$ ) (Liu et al. 2010). PP1 $\gamma$ dephosphorylates substrates of Aurora B kinase such as $\mathrm{Ndc} 80$, and dephosphorylated $\mathrm{Ndc} 80$ binds tightly to spindle microtubules (Liu et al. 2010). Kinase activity of Aurora B is required for error correction of kinetochoremicrotubule attachments, as phosphorylated KMN proteins do not interact with microtubules (Cheeseman et al. 2006; Ciferri et al. 2008; DeLuca et al. 2006; Welburn et al. 2010). Thus, kinetochore substrates for Aurora B must be dephosphorylated to generate proper kinetochore-microtubule attachments, and PP1 $\gamma$-KNL1 contributes to this process (Liu et al. 2010).

KNL1 also interacts with spindle-checkpoint kinases Bub1 and BubR1 through its N-terminal KI motif (Fig. 3) (Bolanos-Garcia et al. 2011; Kiyomitsu et al. 2007; 2011; Krenn et al. 2012). Although depletion of KNL1 causes mislocalization of both Bub1 and BubR1 in human cells (Kiyomitsu et al. 2007), mutant Bub1, which does not bind to KNL1 still localizes to kinetochores. This suggests that KNL1 is a major receptor for such checkpoint proteins, but that these checkpoint proteins have multiple binding sites in kinetochores (Krenn et al. 2012). Bub1 was originally identified as a conserved spindle-checkpoint protein (Hoyt et al. 1991; Taylor and McKeon 1997). A recent study suggested that Bub1 is also involved in the phosphorylation of histone H2A in the centromere region (Fig. 3) (Kawashima et al. 2010). Phosphorylated histone H2A recruits Shugoshin (Sgo1) and Aurora B to the inner centromeres to establish sister-chromatid cohesion at 
the centromere region (Fernius and Hardwick 2005; Kitajima et al. 2005; Perera et al. 2007; Tang et al. 2004; Vaur et al. 2005; Wang et al. 2011; Yamagishi et al. 2010). Thus, KNL1 may become involved in establishment of the inner centromere through its interactions with Bub1.

The $\mathrm{C}$ terminus of KNL1 binds to Zwint- 1 of the RZZ complex or Ns11 and Dsn1 of the Mis12 complex (Kiyomitsu et al. 2007; 2011; Petrovic et al. 2010). Thus, KNL1 interacts directly with the Mis12 complex. However, it is unclear whether KNL1 directly binds to the Ndc80 complex. Kinetochore localization of the Ndc80 complex is not completely abolished in KNL1depleted human or chicken cells, but is completely lost by simultaneous depletion of KNL1 and CENP-K (Cheeseman et al. 2008), suggesting that Ndc80 localization depends on both KNL1-Mis12 and the CCAN. The next major challenge is to address how KNL1 and the CCAN coordinately contribute to the localization of the Ndc80 complex on kinetochores in vertebrate cells.

The Mis12 complex contains four proteins (Nnfl, Mis12, Dsn1, and Ns11) and was identified using a proteomic approach (Cheeseman et al. 2004; Obuse et al. 2004a). Further biochemical analysis confirmed that these four proteins form a stable complex (Kline et al. 2006). The Mis 12 complex acts as a hub to connect other KMN components with kinetochores. Recent structural and biochemical analyses showed that the four subunits of the Mis12 complex form a linear rod-shaped unit with the order: Nnf1, Mis12, Dsn1, and Nsl1. The Nnfl-side faces toward the inner kinetochore and Nnfl directly interacts with CENP-C (Przewloka et al. 2011). Nsl1 faces toward the outer kinetochore and directly binds to both the Ndc80 complex and KNL1 (Kiyomitsu et al. 2010; Petrovic et al. 2010). The PXVXL motif in the Nsl1 C terminus is responsible for interactions with Spc24-Spc25 of the Ndc80 complex (Petrovic et al. 2010). Interestingly, this PXVXL motif also binds to HP1 proteins. Kiyomitsu et al. (2010) proposed that the mitotic function of Nsl1 requires HP1-Ns11 association during interphase. However, the biological significance of the proposed HP1-Ns11 interaction is still unclear.

The Ndc80 complex contains Ndc80, Nuf2, Spc24, and Spc25 and is well conserved (DeLuca et al. 2005; Janke et al. 2001; Martin-Lluesma et al. 2002; McCleland et al. 2003; Hori et al. 2003; Wigge et al. 1998; Wigge and Kilmartin 2001). Structural analysis on the engineered $\mathrm{Ndc} 80^{\text {Bonsai }}$ complex revealed that the $\mathrm{Ndc} 80$ complex has a dumbbell-like shape with a long coiled- coil structure and globular domains at both ends (Ciferri et al. 2008). The globular domains of Spc24 and Spc25 tightly interact with the Mis12 complex, and the Ndc80Nuf2 side of this complex directly binds to the microtubule lattice (Ciferri et al. 2008; DeLuca et al. 2006; Wei et al. 2007). Microtubule interactions of the Ndc 80 complex are electrostatic and is regulated by phosphorylation of the Ndc80 N terminus by Aurora B (Cheeseman et al. 2006; DeLuca et al. 2006; Welburn et al. 2010). However, the detail $\mathrm{N}$ terminus structure of $\mathrm{Ndc} 80$ is still unclear, because the $\mathrm{N}$-terminal tail (1-79aa) is disordered (Ciferri et al. 2008). As the Ndc80 complex is a key factor in ensuring robust interaction of kinetochores with microtubules, major questions in this field include determining how the Ndc 80 complex is recruited to a kinetochore and organizes the kinetochore structure, and how the Ndc80 complex regulates microtubule interaction for accurate chromosome segregation during mitosis and even anaphase. To address these questions, additional structural, biochemical, and cell biological analyses continue.

\section{Creation of an engineered kinetochore}

Following the accumulation of knowledge about kinetochore architecture (Fig. 3), artificial kinetochores may possibly be created to directly understand the molecular assembly of kinetochores. In fact, various groups have tried to create an artificial kinetochore by genetic engineering at a non-centromere region of a chromosome in recent years. This approach was first performed in budding yeast using plasmid DNA (Kiermaier et al. 2009; Lacefield et al. 2009). These experiments revealed that tethering of outer-kinetochore protein Dam1 is sufficient for generation of a functional kinetochore.

Following these experiments, a similar approach was taken in vertebrate or Drosophila cultured cells. In such cases, the bacterial LacO-LacI system has frequently been used. Firstly, a cell line in which an array of $\mathrm{LacO}$ (Lac operator) repeats is integrated into the non-centromere region of a chromosome is established. Then, a LacI (Lac repressor)-fused kinetochore protein is expressed in the cell line with the LacO array, and the LacI fusion protein is expected to be targeted to the LacO array at the non-centromere region. Finally, kinetochore formation in this region is characterized. As CENP-A is a candidate epigenetic marker for kinetochore specification, Barnhart et al. (2011) expressed HJURP, a CENP-A-specific histone chaperone fused to 
LacI (Dunleavy et al. 2009; Foltz et al. 2009) in human U2OS cells with a long LacO array ( $\sim \mathrm{Mb})$ on the arm of chromosome 1. They observed that CENP-A was recruited to the $\mathrm{LacO}$ locus and kinetochore assembly was induced at the LacO locus in LacI-HJURPexpressing cells (Barnhart et al. 2011). Similarly, Mendiburo et al. (2011) tethered CENP-A-GFP-LacI to a non-centromere region in Drosophila S2 cells by the LacO-LacI system and found induction of kinetochore assembly at the non-centromere locus. In addition to formation of these engineered kinetochores, Guse et al. (2011) demonstrated that various kinetochore proteins in Xenopus egg extracts are assembled on CENPA-containing polynucleosomes, assembled in vitro. They also demonstrated that kinetochore assembly did not occur on histone H3-containing polynucleosomes and concluded that six amino acids at the $\mathrm{C}$ terminus of CENP-A are essential for kinetochore assembly. These recent results in genetic engineering studies confirm earlier suggestions that CENP-A provides a mark for kinetochore assembly.

Although CENP-A may work as a mark for kinetochore assembly, it is still unclear which molecules serve as a structural core for kinetochore assembly. We postulate that CENP-T and CENP-C are candidates for this function, because both proteins connect centromeric chromatin located in the inner kinetochore with outer kinetochore proteins. To directly test this possibility, we targeted CENP-T or CENP-C to a LacO array at arm region in both human and chicken cells. Simultaneous tethering of CENP-T and CENP-C into the noncentromere region recruited most kinetochore proteins except for CENP-A at the non-centromere region in human cells (Gascoigne et al. 2011). In addition, we showed that targeting CENP-T-LacI to the LacO locus produced a degree of kinetochore function following removal of the endogenous centromere region using the Cre-loxP system (Gascoigne et al. 2011; Shang et al. 2010). This is the best evidence to date that the induced kinetochore-like structure partially rescued endogenous kinetochore function. As we did not detect CENP-A in the CENP-T- or CENP-C-induced kinetochores, the engineered kinetochore bypasses the requirement for CENP-A nucleosomes. This result is consistent with our model in which CENP-A provides a mark for kinetochore assembly and CENP-T and/or CENP-C functions as a structural core for kinetochore formation. Prendergast et al. (2011) reached a similar conclusion based on FRAP analysis of CENP-A and CENP-T.
Although we showed that an artificial kinetochore could be created on a non-centromeric chromosome arm region, a centromere is usually specified at a single locus of a chromosome and a kinetochore is formed on that centromere. In addition to CENP-A, other CCAN proteins must be involved in the establishment of centromere-specific chromatin, which apparently serves as an epigenetic mark for kinetochore specification. It is thus essential to better define the precise function of each CCAN component. An experimental system based on the engineered kinetochore could facilitate understanding of the functional roles of CCAN.

\section{Conclusion}

The kinetochore is an essential interface with microtubules from the mitotic spindle. Based on EM observations, the kinetochore was visualized as a tri-layered structure in $1960 \mathrm{~s}$, but it was unclear at that time which molecules were involved in the formation of such a structure. Recent studies have revealed that more than 100 proteins are localized to kinetochores and clarified the molecular organization of kinetochores (Fig. 3). This is excellent progress, and we are confident that continued studies will provide us with further knowledge of kinetochore structure and function. The ultimate goal of this field of research will be the creation of artificial functional kinetochores in vitro and their application in vivo. Such a goal was only a kind of dream 50 years ago, but we are now confident that this is achievable in the near future, based on the knowledge being accumulated in this field.

Acknowledgments The authors are very grateful to all members of the Fukagawa Lab for useful discussions. The work of the Fukagawa Lab was supported by Grants-in-Aid for Scientific Research from the Ministry of Education, Culture, Sports, Science and Technology (MEXT) of Japan and the Cabinet Office, Government of Japan through its "Funding Program for the Next Generation World-Leading Researchers". TH was supported by Precursory Research for Embryonic Science and Technology of the Japan Science and Technology Agency and by Grants-in-Aid for Scientific Research from MEXT.

\section{References}

Alonso A, Hasson D, Cheung F, Warburton PE (2010) A paucity of heterochromatin at functional human neocentromeres. Epigenet Chromatin 3:6 
Amano M, Suzuki A, Hori T, Backer C, Okawa K, Cheeseman IM, Fukagawa T (2009) The CENP-S complex is essential for the stable assembly of outer kinetochore structure. $\mathrm{J}$ Cell Biol 186:173-182

Amaro AC, Samora CP, Holtackers R, Wang E, Kingston IJ, Alonso M, Lampson M, McAinsh AD, Meraldi P (2010) Molecular control of kinetochore-microtubule dynamics and chromosome oscillations. Nat Cell Biol 12:319-329

Ando S, Yang H, Nozaki N, Okazaki T, Yoda K (2002) CENP$\mathrm{A},-\mathrm{B}$, and $-\mathrm{C}$ chromatin complex that contains the I-type alpha-satellite array constitutes the prekinetochore in HeLa cells. Mol Cell Biol 22:2229-2241

Barnhart MC, Kuich PH, Stellfox ME, Ward JA, Bassett EA, Black BE, Foltz DR (2011) HJURP is a CENP-A chromatin assembly factor sufficient to form a functional de novo kinetochore. J Cell Biol 194:229-243

Bassett EA, Wood S, Salimian KJ, Ajith S, Foltz DR, Black BE (2010) Epigenetic centromere specification directs aurora $\mathrm{B}$ accumulation but is insufficient to efficiently correct mitotic errors. J Cell Biol 190:177-185

Bierie B, Edwin M, Melenhorst J, Hennighausen L (2004) The proliferation associated nuclear element (PANE1) is conserved between mammals and fish and preferentially expressed in activated lymphoid cells. Gene Expr Patterns 4:389-395

Black BE, Cleveland DW (2011) Epigenetic centromere propagation and the nature of CENP-a nucleosomes. Cell 144: 471-479

Bolanos-Garcia VM, Lischetti T, Matak-Vinkovic D, Cota E, Simpson PJ, Chirgadze DY, Spring DR, Robinson CV, Nilsson J, Blundell TL (2011) Structure of a Blinkin-BUBR1 complex reveals an interaction crucial for kinetochore-mitotic checkpoint regulation via an unanticipated binding site. Structure 19:1691-1700

Brinkley BR, Stubblefield E (1966) The fine structure of the kinetochore of a mammalian cell in vitro. Chromosoma 19:28-43

Carroll CW, Silva MC, Godek KM, Jansen LE, Straight AF (2009) Centromere assembly requires the direct recognition of CENP-A nucleosomes by CENP-N. Nat Cell Biol 11:896-902

Carroll CW, Milks KJ, Straight AF (2010) Dual recognition of CENP-A nucleosomes is required for centromere assembly. J Cell Biol 189:1143-1155

Cheeseman I, Desai A (2008) Molecular architecture of the kinetochore-microtubule interface. Nat Rev Mol Cell Biol 9:33-46

Cheeseman IM, Niessen S, Anderson S, Hyndman F, Yates JR III, Oegema K, Desai A (2004) A conserved protein network controls assembly of the outer kinetochore and its ability to sustain tension. Genes Dev 18:2255-2268

Cheeseman IM, Chappie JS, DA Wilson-Kubalek EM (2006) The conserved KMN network constitutes the core microtubulebinding site of the kinetochore. Cell 127:983-997

Cheeseman IM, Hori T, Fukagawa T, Desai A (2008) KNL1 and the CENP-H/I/K complex coordinately direct kinetochore assembly in vertebrates. Mol Biol Cell 19:587-594

Ciferri C, Pasqualato S, Screpanti E, Varetti G, Santaguida S, Dos RG, Maiolica A, Polka J, De Luca J, De Wulf P, Salek M, Rappsilber J, Moores C, Salmon E, Musacchio A (2008) Implications for kinetochore-microtubule attachment from the structure of an engineered Ndc80 complex. Cell 133: 427-439

Clarke L, Carbon J (1980) Isolation of a yeast centromere and construction of functional small circular chromosomes. Nature 287:504-509

DeLuca J, Dong Y, Hergert P, Strauss J, Hickey J, Salmon E, McEwen B (2005) Hec1 and nuf2 are core components of the kinetochore outer plate essential for organizing microtubule attachment sites. Mol Biol Cell 16:519-531

DeLuca J, Gall W, Ciferri C, Cimini D, Musacchio A, Salmon E (2006) Kinetochore microtubule dynamics and attachment stability are regulated by Hec1. Cell 127:969-982

Desai A, Rybina S, Muller-Reichert T, Shevchenko A, Shevchenko A, Hyman A, Oegema K (2003) KNL-1 directs assembly of the microtubule-binding interface of the kinetochore in $C$. elegans. Genes Dev 17:2421-2435

du Sart D, Cancilla MR, Earle E, Mao JI, Saffery R, Tainton KM, Kalitsis P, Martyn J, Barry AE, Choo KH (1997) A functional neo-centromere formed through activation of a latent human centromere and consisting of non-alphasatellite DNA. Nat Genet 16:144-153

Dunleavy EM, Roche D, Tagami H, Lacoste N, Ray-Gallet D, Nakamura Y, Daigo Y, Nakatani Y, Almouzni-Pettinotti G (2009) HJURP is a cell-cycle-dependent maintenance and deposition factor of CENP-A at centromeres. Cell 137: 485-497

Earnshaw W, Rothfield N (1985) Identification of a family of human centromere proteins using autoimmune sera from patients with scleroderma. Chromosoma 91:313-321

Earnshaw WC, Ratrie H III, Stetten G (1989) Visualization of centromere proteins CENP-B and CENP-C on a stable dicentric chromosome in cytological spreads. Chromosoma 98:1-12

Elowe S, Hummer S, Uldschmid A, Li X, Nigg EA (2007) Tension-sensitive Plk1 phosphorylation on BubR1 regulates the stability of kinetochore microtubule interactions. Genes Dev 21:2205-2219

Espeut J, Cheerambathur DK, Krenning L, Oegema K, Desai A (2012) Microtubule binding by KNL-1 contributes to spindle checkpoint silencing at the kinetochore. J Cell Biol 196:469482

Fernius J, Hardwick KG (2005) Bub1 kinase targets Sgol to ensure efficient chromosome biorientation in budding yeast mitosis. PLoS Genet 3:e213

Folco HD, Pidoux AL, Urano T, Allshire RC (2008) Heterochromatin and RNAi are required to establish CENP-A chromatin at centromeres. Science 319:94-97

Foltz DR, Jansen LET, Black BE, Bailey AO, YateIII JR, Cleveland DW (2006) The human CENP-A centromeric nucleosome-associated complex. Nat Cell Biol 8:458-469

Foltz DR, Jansen LE, Bailey AO, Yates JR III, Bassett EA, Wood S, Black BE, Cleveland DW (2009) Centromerespecific assembly of CENP-a nucleosomes is mediated by HJURP. Cell 137:472-484

Fukagawa T, Mikami Y, Nishihashi A, Regnier V, Haraguchi T, Hiraoka Y, Sugata N, Todokoro K, Brown W, Ikemura T (2001) CENP-H, a constitutive centromere component, is required for centromere targeting of CENP-C in vertebrate cells. EMBO J 20:4603-4617

Gascoigne KE, Takeuchi K, Suzuki A, Hori T, Fukagawa T, Cheeseman IM (2011) Induced ectopic kinetochore assembly 
bypasses the requirement for CENP-A nucleosomes. Cell 145:410-422

Goto H, Kiyono T, Tomono Y, Kawajiri A, Urano T, Furukawa K, Nigg EA, Inagaki M (2006) Complex formation of Plk1 and INCENP required for metaphase-anaphase transition. Nat Cell Biol 8:180-187

Guse A, Carroll CW, Moree B, Fuller CJ, Straight AF (2011) In vitro centromere and kinetochore assembly on defined chromatin templates. Nature 477:354-358

Hanissian SH, Akbar U, Teng B, Janjetovic Z, Hoffmann A, Hitzler JK, Iscove N, Hamre K, Du X, Tong Y, Mukatira S, Robertson JH, Morris SW (2004) cDNA cloning and characterization of a novel gene encoding the MLF1-interacting protein MLF1IP. Oncogene 23:3700-3707

Harrington J, Van Bokkelen G, Mays R, Gustashaw K, Willard H (1997) Formation of de novo centromeres and construction of first-generation human artificial microchromosomes. Nat Genet 15:345-355

Hori T, Haraguchi T, Hiraoka Y, Kimura H, Fukagawa T (2003) Dynamic behavior of Nuf2-Hec1 complex that localizes to the centrosome and centromere and is essential for mitotic progression in vertebrate cells. J Cell Sci 116:33473362

Hori T, Amano M, Suzuki A, Backer CB, Welburn JP, Dong Y, McEwen BF, Shang WH, Suzuki E, Okawa K, Cheeseman IM, Fukagawa T (2008a) CCAN makes multiple contacts with centromeric DNA to provide distinct pathways to the outer kinetochore. Cell 135:1039-1052

Hori T, Okada M, Maenaka K, Fukagawa T (2008b) CENP-O class proteins form a stable complex and are required for proper kinetochore function. Mol Biol Cell 19:843-854

Hoyt M, Totis L, Roberts B (1991) S. cerevisiae genes required for cell cycle arrest in response to loss of microtubule function. Cell 66:507-517

Hudson D, Fowler K, Earle E, Saffery R, Kalitsis P, Trowell H, Hill J, Wreford N, de Kretser D, Cancilla M, Howman E, Hii L, Cutts S, Irvine D, Choo K (1998) Centromere protein B null mice are mitotically and meiotically normal but have lower body and testis weights. J Cell Biol 141:309-319

Ikeno M, Grimes B, Okazaki T, Nakano M, Saitoh K, Hoshino H, McGill N, Cooke H, Masumoto H (1998) Construction of YAC-based mammalian artificial chromosomes. Nat Biotechnol 16:431-439

Ishii K, Ogiyama Y, Chikashige Y, Soejima S, Masuda F, Kakuma T, Hiraoka Y, Takahashi K (2008) Heterochromatin integrity affects chromosome reorganization after centromere dysfunction. Science 321:1088-1091

Izuta H, Ikeno M, Suzuki N, Tomonaga T, Nozaki N, Obuse C, Kisu Y, Goshima N, Nomura F, Nomura N, Yoda K (2006) Comprehensive analysis of the ICEN (Interphase Centromere Complex) components enriched in the CENP-A chromatin of human cells. Genes Cells 11:673-684

Janke C, Ortiz J, Lechner J, Shevchenko A, Shevchenko A, Magiera M, Schramm C, Schiebel E (2001) The budding yeast proteins $\mathrm{Spc} 24 \mathrm{p}$ and $\mathrm{Spc} 25 \mathrm{p}$ interact with $\mathrm{Ndc} 80 \mathrm{p}$ and Nuf2p at the kinetochore and are important for kinetochore clustering and checkpoint control. EMBO J 20: 777-791

Johnston K, Joglekar A, Hori T, Suzuki A, Fukagawa T, Salmon ED (2010) Vertebrate kinetochore protein architecture: protein copy number. J Cell Biol 189:937-943
Jokelainen P (1967) The ultrastructure and spatial organization of the metaphase kinetochore in mitotic rat cells. J Ultrastruct Res 19:19-44

Kang Y, Park J, Yu L, Soung N, Yun S, Bang J, Seong Y, Yu H, Garfield S, Veenstra T, Lee K (2006) Self-regulated Plk1 recruitment to kinetochores by the Plk1-PBIP1 interaction is critical for proper chromosome segregation. Mol Cell 24:409-422

Kapoor M, de Oca M, Luna R, Liu G, Lozano G, Cummings C, Mancini M, Ouspenski I, Brinkley B, May G (1998) The cenpB gene is not essential in mice. Chromosoma 107: $570-576$

Kawashima SA, Yamagishi Y, Honda T, Ishiguro K, Watanabe Y (2010) Phosphorylation of H2A by Bub1 prevents chromosomal instability through localizing Shugoshin. Science 327:172-177

Kelly AE, Ghenoiu C, Xue JZ, Zierhut C, Kimura H, Funabiki $\mathrm{H}$ (2010) Survivin reads phosphorylated histone H3 threonine 3 to activate the mitotic kinase Aurora B. Science 330:235-239

Kerres A, Vietmeier-Decker C, Ortiz J, Karig I, Beuter C, Hegemann J, Lechner J, Fleig U (2004) The fission yeast kinetochore component $\mathrm{Spc} 7$ associates with the EB1 family member Mal3 and is required for kinetochore-spindle association. Mol Biol Cell 15:5255-5267

Kiermaier E, Woehrer S, Peng Y, Mechtler K, Westermann S (2009) A Dam1-based artificial kinetochore is sufficient to promote chromosome segregation in budding yeast. Nat Cell Biol 11:1109-1115

Kitajima TS, Hauf S, Ohsugi M, Yamamoto T, Watanabe Y (2005) Human Bub1 defines the persistent cohesion site along the mitotic chromosome by affecting Shugoshin localization. Curr Biol 15:353-359

Kiyomitsu T, Obuse C, Yanagida M (2007) Human Blinkin/ $\mathrm{AF} 15 \mathrm{q} 14$ is required for chromosome alignment and the mitotic checkpoint through direct interaction with Bub1 and BubR1. Dev Cell 13:663-676

Kiyomitsu T, Iwasaki O, Obuse C, Yanagida M (2010) Inner centromere formation requires $\mathrm{hMis} 14$, a trident kinetochore protein that specifically recruits HP1 to human chromosomes. J Cell Biol 188:791-807

Kiyomitsu T, Murakami H, Yanagida M (2011) Protein interaction domain mapping of human kinetochore protein Blinkin reveals a consensus motif for binding of spindle assembly checkpoint proteins Bub1 and BubR1. Mol Cell Biol 31:998-1011

Kline SL, Cheeseman IM, Hori T, Fukagawa T, Desai A (2006) The human Mis12 complex is required for kinetochore assembly and proper chromosome segregation. J Cell Biol 173:9-17

Krenn V, Wehenkel A, Li X, Santaguida S, Musacchio A (2012) Structural analysis reveals features of the spindle checkpoint kinase Bub1-kinetochore subunit Knl1 interaction. J Cell Biol 196:451-467

Kwon MS, Hori T, Okada M, Fukagawa T (2007) CENP-C is involved in chromosome segregation, mitotic checkpoint function, and kinetochore assembly. Mol Biol Cell 18: 2155-2168

Lacefield S, Lau DT, Murray AW (2009) Recruiting a microtubule-binding complex to DNA directs chromosome segregation in budding yeast. Nat Cell Biol 11:1116-1120 
Lenart P, Petronczki M, Steegmaier M, Di Fiore B, Lipp JJ, Hoffmann M, Rettig WJ, Kraut N, Peters JM (2007) The small-molecule inhibitor BI 2536 reveals novel insights into mitotic roles of polo-like kinase 1. Curr Biol 17:304-315

Liu ST, Hittle JC, Jablonski SA, Campbell MS, Yoda K, Yen TJ (2003) Human CENP-I specifies localization of CENP-F, MAD1 and MAD2 to kinetochores and is essential for mitosis. Nat Cell Biol 5:341-345

Liu ST, Rattner JB, Jablonski SA, Yen TJ (2006) Mapping the assembly pathways that specify formation of the trilaminar kinetochore plates in human cells. J Cell Biol 175:41-53

Liu D, Vleugel M, Backer CB, Hori T, Fukagawa T, Cheeseman IM, Lampson MA (2010) Regulated targeting of protein phosphatase 1 to the outer kinetochore by KNL1 opposes Aurora B kinase. J Cell Biol 188:809-820

Marshall O, Chueh A, Wong L, Choo K (2008) Neocentromeres: new insights into centromere structure, disease development, and karyotype evolution. Am J Hum Genet 82:261-282

Martin-Lluesma S, Stucke VM, Nigg EA (2002) Role of Hec1 in spindle checkpoint signaling and kinetochore recruitment of Mad1/Mad2. Science 297:2267-2270

Masumoto H, Masukata H, Muro Y, Nozaki N, Okazaki T (1989) A human centromere antigen (CENP-B) interacts with a short specific sequence in alphoid DNA, a human centromeric satellite. J Cell Biol 109:1963-1973

Matson DR, Demirel PB, Stukenberg PT, Burke DJ (2012) A conserved role for COMA/CENP-H/I/N kinetochore proteins in the spindle checkpoint. Genes Dev 26:542-547

McCleland ML, Gardner RD, Kallio MJ, Daum JR, Gorbsky GJ, Burke DJ, Stukenberg PT (2003) The highly conserved $\mathrm{Ndc} 80$ complex is required for kinetochore assembly, chromosome congression, and spindle checkpoint activity. Genes Dev 17:101-114

Mendiburo MJ, Padeken J, Fulop S, Schepers A, Heun P (2011) Drosophila CENH3 is sufficient for centromere formation. Science 334:686-690

Milks KJ, Moree B, Straight AF (2009) Dissection of CENP-Cdirected centromere and kinetochore assembly. Mol Biol Cell 20:4246-4255

Minoshima Y, Hori T, Okada M, Kimura H, Haraguchi T, Hiraoka Y, Bao YC, Kawashima T, Kitamura T, Fukagawa $\mathrm{T}$ (2005) The constitutive centromere component CENP50 is required for recovery from spindle damage. Mol Cell Biol 25:10315-10328

Moroi Y, Peebles C, Fritzler MJ, Steigerwald J, Tan EM (1980) Autoantibody to centromere (kinetochore) in scleroderma sera. Proc Natl Acad Sci USA 77:1627-1631

Nekrasov VS, Smith MA, Peak-Chew S, Kilmartin JV (2003) Interactions between centromere complexes in Saccharomyces cerevisiae. Mol Biol Cell 14:4931-4946

Nishihashi A, Haraguchi T, Hiraoka Y, Ikemura T, Regnier V, Dodson H, Earnshaw WC, Fukagawa T (2002) CENP-I is essential for centromere function in vertebrate cells. Dev Cell 2:463-476

Nishino T, Takeuchi K, Gascoigne KE, Suzuki A, Hori T, Oyama T, Morikawa K, Cheeseman IM, Fukagawa T (2012) CENP-T-W-S-X forms a unique centromeric chromatin structure with a histone-like fold. Cell 148:487-501

Obuse C, Iwasaki O, Kiyomitsu T, Goshima G, Toyoda Y, Yanagida M (2004a) A conserved Mis12 centromere complex is linked to heterochromatic HP1 and outer kinetochore protein Zwint-1. Nat Cell Biol 6:1135-1141

Obuse C, Yang H, Nozaki N, Goto S, Okazaki T, Yoda K (2004b) Proteomics analysis of the centromere complex from HeLa interphase cells: UV-damaged DNA binding protein 1 (DDB-1) is a component of the CEN-complex, while BMI-1 is transiently co-localized with the centromeric region in interphase. Genes Cells 9:105-120

Ohzeki J, Nakano M, Okada T, Masumoto H (2002) CENP-B box is required for de novo centromere chromatin assembly on human alphoid DNA. J Cell Biol 159:765-775

Okada M, Cheeseman IM, Hori T, Okawa K, McLeod IX, Yates JR III, Desai A, Fukagawa T (2006) The CENP-H-I complex is required for the efficient incorporation of newly synthesized CENP-A into centromeres. Nat Cell Biol 8:446-457

Okada T, Ohzeki J, Nakano M, Yoda K, Brinkley WR, Larionov V, Masumoto H (2007) CENP-B controls centromere formation depending on the chromatin context. Cell 131:12871300

Okada M, Okawa K, Isobe T, Fukagawa T (2009) CENP-Hcontaining complex facilitates centromere deposition of CENP-A in cooperation with FACT and CHD1. Mol Biol Cell 20:3986-3995

Olszak AM, van Essen D, Pereira AJ, Diehl S, Manke T, Maiato H, Saccani S, Heun P (2011) Heterochromatin boundaries are hotspots for de novo kinetochore formation. Nat Cell Biol 13:799-808

Pagliuca C, Draviam VM, Marco E, Sorger PK, De Wulf P (2009) Roles for the conserved spc105p/kre28p complex in kinetochore-microtubule binding and the spindle assembly checkpoint. PLoS One 4:e7640

Palmer D, O'Day K, Wener M, Andrews B, Margolis R (1987) A $17-\mathrm{kD}$ centromere protein (CENP-A) copurifies with nucleosome core particles and with histones. J Cell Biol 104:805-815

Pan HY, Zhang YJ, Wang XP, Deng JH, Zhou FC, Gao SJ (2003) Identification of a novel cellular transcriptional repressor interacting with the latent nuclear antigen of Kaposi's sarcoma-associated herpesvirus. J Virol 77:97589768

Perera D, Tilston V, Hopwood JA, Barchi M, Boot-Handford RP, Taylor SS (2007) Bub1 maintains centromeric cohesion by activation of the spindle checkpoint. Dev Cell 13:566-579

Perez-Castro A, Shamanski F, Meneses J, Lovato T, Vogel K, Moyzis R, Pedersen R (1998) Centromeric protein B null mice are viable with no apparent abnormalities. Dev Biol 201:135-143

Perpelescu M, Fukagawa T (2011) The ABCs of CENPs. Chromosoma 120:425-446

Petrovic A, Pasqualato S, Dube P, Krenn V, Santaguida S, Cittaro D, Monzani S, Massimiliano L, Keller J, Tarricone A, Maiolica A, Stark H, Musacchio A (2010) The MIS12 complex is a protein interaction hub for outer kinetochore assembly. J Cell Biol 190:835-852

Prendergast L, van Vuuren C, Kaczmarczyk A, Doering V, Hellwig D, Quinn N, Hoischen C, Diekmann S, Sullivan KF (2011) Premitotic assembly of human CENPs -T and -W switches centromeric chromatin to a mitotic state. PLoS Biol 9: e1001082 
Przewloka MR, Zhang W, Costa P, Archambault V, D'Avino PP, Lilley KS, Laue ED, McAinsh AD, Glover DM (2007) Molecular analysis of core kinetochore composition and assembly in Drosophila melanogaster. PLoS One 2:e478

Przewloka MR, Venkei Z, Bolanos-Garcia VM, Debski J, Dadlez M, Glover DM (2011) CENP-C is a structural platform for kinetochore assembly. Curr Biol 21:399-405

Regnier V, Vagnarelli P, Fukagawa T, Zerjal T, Burns E, Trouche D, Earnshaw W, Brown W (2005) CENP-A is required for accurate chromosome segregation and sustained kinetochore association of BubR1. Mol Cell Biol 25:3967-3981

Renou JP, Bierie B, Miyoshi K, Cui Y, Djiane J, Reichenstein M, Shani M, Henninghauzen L (2003) Identification of genes differentially expressed in mouse mammary epithelium transformed by an activated b-catenin. Oncogene 22:4594-461

Ribeiro SA, Vagnarelli P, Dong Y, Hori T, McEwen BF, Fukagawa T, Flors C, Earnshaw WC (2010) A super-resolution map of the vertebrate kinetochore. Proc Natl Acad Sci USA 107: 10484-10489

Saitoh H, Tomkiel J, Cooke C, Ratrie H III, Maurer M, Rothfield N, Earnshaw WC (1992) CENP-C, an autoantigen in scleroderma, is a component of the human inner kinetochore plate. Cell 70:115-125

Saitoh S, Takahashi K, Yanagida M (1997) Mis6, a fission yeast inner centromere protein, acts during G1/S and forms specialized chromatin required for equal segregation. Cell 90:131-143

Santamaria A, Wang B, Elowe S, Malik R, Zhang F, Bauer M, Schmidt A, Sillje HH, Korner R, Nigg EA (2011) The Plk1dependent phosphoproteome of the early mitotic spindle. Mol Cell Proteomics 10:M110.004457

Screpanti E, De Antoni A, Alushin GM, Petrovic A, Melis T, Nogales E, Musacchio A (2011) Direct binding of Cenp-C to the Mis12 complex joins the inner and outer kinetochore. Curr Biol 21:391-398

Shang WH, Hori T, Toyoda A, Kato J, Popendorf K, Sakakibara Y, Fujiyama A, Fukagawa T (2010) Chickens possess centromeres with both extended tandem repeats and short nontandem-repetitive sequences. Genome Res 20:1219-1228

Sugata N, Munekata E, Todokoro K (1999) Characterization of a novel kinetochore protein, CENP-H. J Biol Chem 274: 27343-27346

Sullivan BA, Schwartz S (1995) Identification of centromeric antigens in dicentric Robertsonian translocations: CENP-C and CENP-E are necessary components of functional centromeres. Hum Mol Genet 4:2189-2197

Suzuki A, Hori T, Nishino T, Usukura J, Miyagi A, Morikawa K, Fukagawa T (2011) Spindle microtubules generate tensiondependent changes in the distribution of inner kinetochore proteins. J Cell Biol 193:125-140

Tachiwana H, Kagawa W, Shiga T, Osakabe A, Miya Y, Saito K, Hayashi-Takanaka Y, Oda T, Sato M, Park SY, Kimura H, Kurumizaka H (2011) Crystal structure of the human centromeric nucleosome containing CENP-A. Nature 476:232-235

Takeuchi K, Fukagawa T (2012) Molecular architecture of vertebrate kinetochores. Exp Cell Res 318:1367-1374
Tang Z, Sun Y, Harley SE, Zou H, Yu H (2004) Human Bub1 protects centromeric sister-chromatid cohesion through Shugoshin during mitosis. Proc Natl Acad Sci USA 101:1801218017

Taylor S, McKeon F (1997) Kinetochore localization of murine Bub1 is required for normal mitotic timing and checkpoint response to spindle damage. Cell 89:727-735

Vafa O, Sullivan KF (1997) Chromatin containing CENP-A and alpha-satellite DNA is a major component of the inner kinetochore plate. Curr Biol 7:897-900

Vaur S, Cubizolles F, Plane G, Genier S, Rabitsch PK, Gregan J, Nasmyth K, Vanoosthuyse V, Hardwick KG, Javerzat JP (2005) Control of Shugoshin function during fission-yeast meiosis. Curr Biol 15:2263-2270

Wade CM, Giulotto E, Sigurdsson S, Zoli M, Gnerre S, Imsland F, Lear TL, Adelson DL, Bailey E, Bellone RR, Blocker H, Distl O, Edgar RC, Garber M, Leeb T, Mauceli E, MacLeod JN, Penedo MC, Raison JM, Sharpe T, Vogel J, Andersson L, Antczak DF, Biagi T, Binns MM, Chowdhary BP, Coleman SJ, Della Valle G, Fryc S, Guerin G, Hasegawa T, Hill EW, Jurka J, Kiialainen A, Lindgren G, Liu J, Magnani E, Mickelson JR, Murray J, Nergadze SG, Onofrio R, Pedroni S, Piras MF, Raudsepp T, Rocchi M, Roed KH, Ryder OA, Searle S, Skow L, Swinburne JE, Syvanen AC, Tozaki T, Valberg SJ, Vaudin M, White JR, Zody MC, Lander ES, Lindblad-Toh K (2009) Genome sequence, comparative analysis, and population genetics of the domestic horse. Science 326:865-867

Wang F, Dai J, Daum JR, Niedzialkowska E, Banerjee B, Stukenberg PT, Gorbsky GJ, Higgins JM (2010) Histone H3 Thr-3 phosphorylation by Haspin positions Aurora B at centromeres in mitosis. Science 330:231-235

Wang F, Ulyanova NP, van der Waal MS, Patnaik D, Lens SM, Higgins JM (2011) A positive feedback loop involving Haspin and Aurora B promotes CPC accumulation at centromeres in mitosis. Curr Biol 21:1061-1069

Warburton PE, Cooke CA, Bourassa S, Vafa O, Sullivan BA, Stetten G, Gimelli G, Warburton D, Tyler-Smith C, Sullivan KF, Poirier GG, Earnshaw WC (1997) Immunolocalization of CENP-A suggests a distinct nucleosome structure at the inner kinetochore plate of active centromeres. Curr Biol 7:901-904

Wei R, Al-Bassam J, Harrison S (2007) The Ndc80/HEC1 complex is a contact point for kinetochore-microtubule attachment. Nat Struct Mol Biol 14:54-59

Welburn JP, Vleugel M, Liu D, Yates JR III, Lampson MA, Fukagawa T, Cheeseman IM (2010) Aurora B phosphorylates spatially distinct targets to differentially regulate the kinetochore-microtubule interface. Mol Cell 38:383-392

Wiens GR, Sorger PK (1998) Centromeric chromatin and epigenetic effects in kinetochore assembly. Cell 93:313-316

Wigge P, Kilmartin J (2001) The Ndc80p complex from Saccharomyces cerevisiae contains conserved centromere components and has a function in chromosome segregation. J Cell Biol 152:349-360

Wigge P, Jensen O, Holmes S, Souès S, Mann M, Kilmartin J (1998) Analysis of the Saccharomyces spindle pole by 
matrix-assisted laser desorption/ionization (MALDI) mass spectrometry. J Cell Biol 141:967-977

Willard HF (1990) Centromeres of mammalian chromosomes. Trends Genet 6:410-416

Yamagishi Y, Honda T, Tanno Y, Watanabe Y (2010) Two histone marks establish the inner centromere and chromosome bi-orientation. Science 330:239-243
Yamashita A, Ito M, Takamatsu N, Shiba T (2000) Characterization of Solt, a novel SoxLZ/Sox6 binding protein expressed in adult mouse testis. FEBS Lett 481:147-151

Yang CH, Tomkiel J, Saitoh H, Johnson D, Earnshaw W (1996) Identification of overlapping DNA-binding and centromeretargeting domains in the human kinetochore protein CENPC. Mol Cell Biol 16:3576-3586 